\title{
Avances en el conocimiento de las proteínas de la leche materna
}

\author{
Advances in the knowledge about human milk proteins
}

\author{
Oscar Brunser ${ }^{\mathrm{a}}$
}

aProfesor Titular de Pediatría, Facultad de Medicina, Universidad de Chile. Pediatra, Gastroenterólogo, Nestlé de Chile

Recibido el 25 de abril de 2017; aceptado el 12 de octubre de 2017

\begin{abstract}
Resumen
La glándula mamaria y la leche materna son el resultado de millones de años de una evolución que llevó a una composición óptima para el crecimiento y desarrollo de recién nacidos y lactantes; la leche materna favorece el crecimiento, la adaptación y la supervivencia de su organismo y de sus órganos inmaduros. Análisis recientes han demostrado en ella la presencia de 1606 proteínas que en su mayoría son sintetizadas en los acinos de la glándula mamaria aunque otras proteínas y péptidos provienen de órganos como el sistema linfático y el aparato digestivo. La composición de la leche materna incluye enzimas que modifican sus proteínas y originan péptidos antimicrobianos, antihipertensivos y estimuladores del metabolismo. Esta actividad proteolítica actúa en sitios específicos de las cadenas peptídicas de la proteína de la leche. La activación extemporánea de estos enzimas en los acinos es regulada por péptidos inhibidores y activadores que previenen procesos inflamatorios. Algunos enzimas de la leche actúan en el tubo digestivo de recién nacidos y lactantes y complementan la menor concentración y actividad de sus propios enzimas digestivos. Así, la enteroquinasa de la leche estimula la liberación de enzimas pancreáticos (mediada por el estímulo de la colecistoquininapancreozimina); la lipasa activada por las sales biliares complementa la baja producción de lipasa pancreática. Estas actividades probablemente facilitan la nutrición de los prematuros, cuyo tubo digestivo es más permeable a las proteínas parcialmente hidrolizadas y cuyas actividades enzimáticas y factores defensivos locales no han alcanzado su plena madurez. Esto también puede estimular en ellos la tolerancia inmunológica. En este artículo se presentan los aspectos fisiológicos relevantes de la leche materna, y los avances en el conocimiento de su composición, para el cabal conocimiento del pediatra de esta importante materia.
\end{abstract}

\begin{abstract}
The mammary gland and maternal milk are the product of millions of years of evolution that resulted in an optimal composition that sustains the growth and development of newborns and infants. Maternal milk supports the growth, adaptation and survival of this immature organism. Recent studies have detected 1606 different proteins in human milk, most of them synthesized in the acini of the glandular tissue while others originate from distant organs such as the lymphoid tissue and the digestive tract. Maternal milk enzymes modify its proteins and liberate peptides with antimicrobial, antihypertensive or stimulatory activities. This proteolytic activity occurs at specific sites in peptide
\end{abstract}

Palabras clave: Leche materna; enzimas; péptidos; tripsina; plasmina

Keywords: Breast milk; enzymes; peptides; trypsin; plasmin 
chains. To prevent the extemporaneous activation of these proteolytic enzymes, that would result in inflammatory processes, maternal milk also contains inhibitory peptides that together with the stimulatory peptides conform a complex regulatory system. Some enzymes in maternal milk maintain their activity in the gastrointestinal tract of infants and compensate for the decreased activity of digestive tract enzymes in newborns. Thus, the milk enterokynase stimulates the release of pancreatic proteases as it induces the liberation of cholecystokynin/pancreozymin. The bile salt-activated lipase of human milk is activated in the duodenum by the infants' bile salts and partially compensates for the low levels of pancreatic lipase in newborns. These milk enzymes probably contribute to the nutrition of premature infants as they increase the availability of amino acids and peptides in their upper gastrointestinal tract; furthermore, as their intestinal epithelium is more permeable to peptides and partially digested protein this may help induce immune tolerance. The most relevant issues in the physiology and composition of the maternal milk are presented in this review.

\section{Evolución de la glándula mamaria y la secreción de leche en los mamíferos}

La leche materna es el producto de un proceso evolutivo que se estima se ha producido a lo largo de unos 200 millones de años. Existe evidencia que sugiere que las primitivas glándulas mamarias se habrían desarrollado en animales terrestres antecesores de los mamíferos, que gestaban a sus crías en una especie de amnios. En algún momento antes del nacimiento, los embriones eran incorporados a estructuras parecidas a huevos pero con una cubierta blanda, semejante por su consistencia parecida al pergamino a los huevos de las actuales tortugas marinas; esta cáscara era muy diferente de la dura cáscara cálcica de los huevos de las aves cuyos sitios de nidación eran muy variados y expuestos al aire. Al quedar expuestos al ambiente, los huevos de cáscara blanda perdían agua rápidamente a través de su cáscara, lo que dificultaba incubarlos en un nido y debieron ser depositados en la vecindad de cursos de agua, como lo hacen en la actualidad las tortugas marinas. En algún momento de la evolución los embriones habrían comenzado a ser incubados en el cuerpo materno en una especie de bolsillo en el que, desde zonas especializadas de su revestimiento interno, se vertía una secreción acuosa. La cubierta semipermeable del huevo habría permitido el paso de agua, nutrientes y electrolitos al interior del huevo. Este proceso guarda algunas semejanzas con lo que se observa en el ornitorrinco, que todavía aloja huevos con cáscara blanda en una cavidad corporal ${ }^{1}$.

A lo largo de la evolución, el tegumento de los bolsillos donde los mamíferos primitivos incubaban sus huevos se fue diferenciando y esto se asoció con el desarrollo de folículos pilosos y glándulas sebáceas que se vaciaban en una especie de pezones primitivos; la creciente complejidad de estas estructuras llevó finalmente a la desaparición de los folículos pilosos. Con el tiempo las glándulas secretoras desarrollaron otras funciones llegado a sintetizar un disacárido característico, la lactosa. Se puede especular que la composi- ción del líquido secretado por las glándulas mamarias primitivas fue aumentando en su complejidad, lo que permitió la disminución del tamaño del huevo e hizo que la cría, muy pequeña al nacer, se volviera mucho más dependiente de la calidad y el volumen de esta secreción nutritiva. En los mamíferos, estas estructuras derivadas del ectodermo se transformaron en mamas que se desarrollaron en territorios definidos en la pared del tórax y el abdomen, denominados las "líneas de la leche" ${ }^{\text {. }}$. El resultado de este proceso evolutivo llevó a que la leche materna llegara a incluir en su composición no sólo proteínas con alta calidad nutricional sino a todos los nutrientes que los recién nacidos requieren para su adecuado crecimiento y desarrollo ${ }^{3}$.

\section{Complejidad del proteoma de la leche materna}

El proceso evolutivo llevó a que las proteínas de la leche humana, además de una fuente de aminoácidos indispensables para la síntesis de proteínas endógenas de los recién nacidos, representaran una mezcla compleja de moléculas cuya composición y funciones fueron bastante similares a las de otros mamíferos, como es el caso de la leche de vaca o incluso de primates. Esta complejidad de la leche materna ha sido objeto de un estudio reciente muy detallado que reveló su carácter único ${ }^{4}$. En dicho estudio se emplearon metódicas de aislamiento y análisis de alta resolución para identificar proteínas en muestras de leche madura de mujeres sanas; estos resultados fueron comparados con la composición de la leche de hembras de mono rhesus (Macaca mulata). Una de las razones para esta comparación es que tanto la leche humana como la de mono rhesus tienen proporciones caseína/proteínas del suero semejantes (60/40) y además las crías de rhesus se desarrollan normalmente al ser alimentadas con fórmulas infantiles, lo que no pasa con otros simios. Brevemente, las muestras de leche fueron centrifugadas para extraer sus lípidos, fueron tratadas con carbohidrasas para digerir y eliminar sus hidratos de carbono sim- 
ples y complejos y finalmente quedaron las proteínas, que fueron purificadas, separadas por electroforesis y digeridas con proteasas para fraccionarlas en péptidos largos. La composición de aminoácidos de cada uno de los péptidos resultantes fue determinada mediante una combinación de cromatografía seguida de espectrometría de masa en tándem. La secuencia de aminoácidos de cada péptido fue reconstruida a partir de catálogos de la estructura de aminoácidos de cada proteína. En la leche humana se detectaron 1.606 proteínas diferentes y 518 en la de mono rhesus. De las proteínas de la leche materna 524 no habían sido descritas anteriormente y sus funciones son desconocidas. La complejidad del funcionamiento de la glándula mamaria humana también quedó de manifiesto cuando otros investigadores demostraron que durante la lactancia están activados en la glándula mamaria 10.000 genes (de los 23.000 que componen el genoma humano $)^{5}$. De las proteínas detectadas en la leche humana, 83 son diferencialmente abundantes ${ }^{4,5}$ e incluyen la lactoferrina, el receptor de inmunoglobulinas poliméricas (IgA e IgM), la $\alpha 1$ antitripsina, la lipasa estimulada por las sales biliares (BSSL), la proteína transportadora de vitamina D y la haptocorrina (también llamada transcobalamina-1 y proteína ligadora de vitamina $\mathrm{B}_{12}$ ). Las proteínas más abundantes en la leche materna están asociadas con el desarrollo del tracto gastrointestinal, el sistema nervioso central y la inmunidad del recién nacido y el lactante. Estos hallazgos sugieren que las proteínas de la leche materna apoyan no sólo el crecimiento del lactante sino también la maduración de sus órganos y sistemas y contribuyen a la protección frente a carencias específicas de minerales y vitaminas ${ }^{4}$.

\section{Enzimas proteolíticos en la glándula mamaria y la leche materna}

Además de proteínas, la leche materna contiene péptidos de diversos tamaños de los que sólo algunas de sus capacidades funcionales son conocidas. Por ejemplo, algunos péptidos tienen actividad antimicrobiana y son producidos durante la digestión in situ de la $\beta$-caseína. La presencia de péptidos en la secreción láctea significa que en los acinos de la glándula mamaria y/o en sus conductos secretorios actúan enzimas proteolíticos que generan algunos de los diferentes péptidos; algunos de ellos son de tamaño considerable, y sus actividades deben ser beneficiosas para los lactantes.

De los enzimas presentes en la leche materna, muchos han sido estudiados extensamente en la leche de bovinos y dos de los más importantes son la plasmina y la tripsina; además de actuar sobre la $\beta$-caseína, la tripsina y la plasmina actúan también sobre el receptor polimérico de las inmunoglobulinas y sobre la osteopontina, la caseína- $\alpha_{S_{1}}$ y sobre componentes proteicos de la membrana de los glóbulos de grasa. Estos enzimas actúan a nivel de las cadenas peptídicas, en partes de las moléculas que están físicamente al alcance de sus sitios activos y para esto usan como señal algunos aminoácidos, como la lisina y la arginina en caso de la tripsina y de la digestión de la $\beta$-caseína; en cambio, en la mismas $\beta$-caseína los mismos enzimas no actúan sobre uniones peptídicas idénticas pero situadas en partes profundas de la estructura terciaria y cuaternaria de la molécula, a las que el sitio activo de la tripsina y la plasmina físicamente no tienen acceso ${ }^{6,7}$. Otro factor que explica los cambios que los enzimas proteolíticos introducen en las proteínas de la leche materna es su efecto en la secuencia de sus aminoácidos: en el caso de la tripsina, y como se expresó anteriormente, su actividad específica se expresa a partir del terminal carboxílico, en enlaces en que participan una lisina o una arginina. Sin embargo, el enzima no actúa en estos mismos enlaces si los aminoácidos contiguos a la arginina o la lisina son una o más prolinas ${ }^{6}$. En este proceso de fraccionamiento de la cadena peptídica no sólo importa la secuencia de aminoácidos sino también su disposición espacial, resultante de su plegamiento terciario y cuaternario, que limita el número de enlaces que los enzimas físicamente pueden hidrolizar. Esto probablemente significa que durante la evolución, junto con la generación de sitios específicos para este proceso de hidrólisis, las actividades proteolíticas representaron cambios que llevaron a la síntesis de determinados péptidos cuyas capacidades fueron beneficiosas para el desarrollo de los lactantes ${ }^{5}$.

Además de la tripsina y la plasmina, en la leche materna han sido identificados diversos otros enzimas proteolíticos: de estos los más estudiados son la elastasa, la catepsina D, la pepsina y la quimotripsina. Algunos de ellos son muy activos pero, como en los ejemplos anteriores, si bien en las proteínas de la leche hay un número de posibles enlaces peptídicos sobre los que pudieran actuar, en la realidad terminan hidrolizados muchos menos. Por ejemplo la catepsina D potencialmente podría hidrolizar 846 enlaces en la proteínas de la leche pero, al estudiar los productos de su actividad es evidente que sólo actúa en 130 sitios; en la molécula de $\beta$-caseína, sobre la que ejerce considerable actividad enzimática, actúa sólo en 78 sitios y en el receptor para la inmunoglobulina polimérica hidroliza 21 enlaces ${ }^{8,9}$.

En la leche materna es posible identificar una elastasa pero esta proviene de leucocitos neutrófilos y por este motivo su presencia en la leche indica la probable existencia de una mastitis ${ }^{10}$. La elastasa y la catepsina $\mathrm{D}$ teóricamente pueden actuar sobre estos enlaces pero esto no siempre ocurre debido en gran parte a la conformación espacial de sus sustratos; por ejemplo, la elastasa actúa principalmente sobre la $\beta$-caseína y el 
receptor para la inmunoglobulina polimérica, en 41 y 25 enlaces, respectivamente. Ambos enzimas modifican las proteínas de la leche materna antes que sea consumida por el niño, actuando sobre enlaces diferentes de aquellos hidrolizados por la plasmina y la tripsina ${ }^{6,7}$. Esta descripción somera da una idea de la complejidad del proceso de hidrólisis y contribuye a explicar el origen de la variedad de péptidos presentes en la leche madura.

La tabla 1 muestra algunas de las proteínas de la leche materna que son digeridas por la tripsina y el número de enlaces hidrolizados.

Un aspecto importante de esta descripción es aclarar si el origen de los enzimas presentes en la leche materna es la glándula mamaria o si provienen de otros órganos. De los enzimas detectados en la leche materna un número limitado tiene su origen en la glándula mamaria. Por ejemplo, el gen que codifica la tripsina no ha sido detectado en el tejido mamario, por lo que lo más probable es que su origen sea pancreático; tampoco se detectó en la glándula el gen de la plasmina. El mecanismo que transporta a estos y otros enzimas a la glándula, y si lo son estando en forma activa o inactiva, se desconoce. La catepsina D está altamente expresada en el tejido mamario y la elastasa probablemente pro-

\begin{tabular}{|c|c|}
\hline Proteína & $\begin{array}{l}\mathrm{n} \text { de enlaces } \\
\text { hidrolizados }\end{array}$ \\
\hline$\beta$-caseína & 89 \\
\hline Receptor polimérico de inmunoglobulinas & 32 \\
\hline Osteopontina & 18 \\
\hline Butirofilina & 15 \\
\hline Caseína- $\alpha_{s 1}$ & 11 \\
\hline Caseína-к & 7 \\
\hline Mucina-1 & 3 \\
\hline Proteína relacionada con la hormona paratiroidea & 2 \\
\hline Lipasa activada por las sales biliares (BSSL) & 2 \\
\hline Proteína relacionada con La & 1 \\
\hline Homólogo de la proteína diáfana 1 & 1 \\
\hline Proteína 2 regulada por el receptor NMDA & 1 \\
\hline Factor C4-A del complemento & 1 \\
\hline Proteína 1 del sistema indicador para la citoquinesis & 1 \\
\hline
\end{tabular}

Las proteínas están ordenadas en base al número de enlaces hidrolizados por la tripsina en cada una de ellas. Se ha considerado el número de péptidos únicos; si un péptido no era único se consideró una sola copia de él. Las proteínas encontradas únicamente en la leche humana están impresas en negrita. Modificado de Dallas DC et al. J Mammary Gland Biol Neoplasia 2015; 20: 133-47. viene de polimorfonucleares. Al evaluar en el páncreas el material genético que codifica algunos de estos enzimas, se observa que su estructura es idéntica a la a los detectados en la leche, lo que apoya la idea de un origen común ${ }^{8}$.

\section{Péptidos encriptados en la estructura de proteínas de la leche materna}

Desde hace muchos años se sabe que en la secuencia de los aminoácidos que forman las proteínas de la leche está incluido un número de péptidos, que han sido denominados encriptados y que, una vez liberados por hidrólisis enzimática, poseen actividades biológicas ${ }^{11}$. Por ejemplo, algunos de ellos participan en el organismo inmaduro en el desarrollo y la protección de su tubo digestivo, y en órganos extradigestivos de los recién nacidos ${ }^{12,13}$. La hidrólisis sucesiva de la $\beta$-caseína por la tripsina, la pepsina, la quimotripsina, la gama-glutamil endopeptidasa y probablemente otros enzimas, libera un péptido del que se origina una familia de cuatro componentes con fuerte actividad antimicrobiana; estos se caracterizan porque la cadena de aminoácidos de cada uno de ellos es, respectivamente, un aminoácido más corta que la del homólogo que la precede ${ }^{12,14}$. Es probable que las actividades antimicrobianas de algunos de los péptidos originados de la leche materna coincidan en sus actividades y se potencien entre $\mathrm{si}^{15}$. Es posible también que algunos de estos péptidos resistan la proteolisis por los enzimas del tubo digestivo; considerada desde este punto de visto, la leche materna representaría un factor protector de toda la extensión del tubo digestivo del lactante ${ }^{14}$.

La especificidad de la proteólisis en la glándula mamaria queda demostrada también porque la $\beta$-caseína, muy susceptible a procesos de hidrólisis en la leche misma, es el origen de numerosos péptidos que han sido demostrados en diversos estudios. Contrastando con esto, las caseínas $\alpha_{s 1}$ y $\kappa$, son más resistentes a la hidrólisis enzimática en la glándula mamaria y sirven de origen a relativamente pocos péptidos. En la composición de estas tres proteínas no existen grandes diferencias en la frecuencia de arginina y lisina; incluso la $\beta$-caseína tiene un menor número de ambos aminoácidos; esto sugiere que sus distintas susceptibilidades a la acción enzimática se debería a otros factores, uno de los cuales deberían ser sus estructuras terciaria y cuaternaria, que bloquean la acción de los enzimas proteolíticos ${ }^{6}$. Otras proteínas, como la $\alpha$-lactoalbúmina y la lactoferrina también son resistentes a la actividad proteolítica de los enzimas presentes en la leche, lo que probablemente, como en el caso anterior, es explicado por la secuencia de sus aminoácidos y por su estructura terciaria y cuaternaria ${ }^{16,17}$. 


\section{Control de las actividades de los enzimas de la leche materna.}

Además de proteasas, la leche materna contiene moléculas con capacidad para inhibir la actividad de algunos de estos enzimas, como es el caso de la $\alpha-1$ antitripsina y la $\alpha$-1-antiquimotripsina ${ }^{18}$. A esto se agrega la presencia en la glándula y en la leche de otras moléculas enzimáticas con efectos activadores; esto completa un complejo sistema de control, con capacidad ya sea de activación de la digestión enzimática de las proteínas o de detener este proceso; los mecanismos que controlan este conjunto de enzimas y sus actividades son desconocidos. Algunos de los enzimas de la leche materna mantienen su actividad en el tubo digestivo del lactante; otros, sintetizados en forma inactiva en la glándula mamaria son activados en su intestino; el mejor ejemplo de este último tipo es la lipasa estimulada por las sales biliares (BSSL, bile salt-stimulated lipase, por su denominación en inglés), enzima que es sintetizada en la glándula mamaria y activada en el duodeno del lactante por su sales biliares ${ }^{19}$. Este sistema compensa en parte de los bajos niveles de lipasa en la secreción pancreática durante los primeros meses de vida del recién nacido. Esta forma de activación de la lipasa de la leche materna evita que si el enzima se activara en la glándula mamaria se desarrolle un proceso inflamatorio inducido por los ácidos grasos libres derivados de la lipólisis de triglicéridos ${ }^{20}$. Aunque la actividad de algunos enzimas secretados por la glándula mamaria persiste sin mayores cambios a lo largo de la lactancia (catepsina-D, elastasa, plasmina), la actividad de otros decrece paulatinamente $e^{8,18}$.

La fracción del total de las proteínas de la leche que es modificada por los enzimas es relativamente menor pero parte de su importancia reside en que algunos péptidos pasan a formar parte de la membrana externa de los glóbulos de lípidos de la leche $e^{21,22}$.

\section{Origen de las proteínas de la leche materna}

El origen de las proteínas de la leche materna es múltiple: la mayoría es sintetizada en los acinos de la glándula mamaria a partir de aminoácidos libres o de péptidos cortos aportados por la circulación sanguínea; estos deben llegar al citoplasma de las células acinares mediante transportadores específicos presentes en la membrana plasmática basolateral de dichas células $^{23}$. En ellas la síntesis de las proteínas es realizada por mecanismos iguales a los de los demás tejidos del organismo $^{24}$. La identificación de los respectivos ARN mensajeros (ARNm) en las células de los acinos permite identificar aquellas proteínas (proteasas, inhibidores, estimuladores, etc.) que son sintetizadas local- mente y sirve además para evidenciar cuales de ellas son sintetizadas en otros órganos y aportadas a la leche materna desde la circulación sanguínea. Las proteínas más estudiadas en cuanto a su transporte desde la circulación sanguínea son las inmunoglobulinas A y M, la transferrina y la prolactina, que son traspasadas intactas a la secreción láctea ${ }^{25}$. Esto es corroborado por la ausencia de su ARNm en las células acinares aisladas de la leche mediante centrifugación ${ }^{26}$. Lo más probable es que estas proteínas lleguen a la leche por transcitosis después de atravesar el epitelio de los acinos glandulares; incluso existiría la posibilidad de que atraviesen el epitelio de los conductos secretores por mecanismos que tampoco han sido determinados; no está claro si durante este transporte transcelular estas moléculas sufren cambios en su estructura. Otras moléculas de la leche materna, principalmente inmunoglobulinas, son sintetizadas in situ por células del sistema inmune que migran a los acinos y a la leche: se trata principalmente de linfocitos, macrófagos y algunos escasos neutrófi$\operatorname{los}^{25,27}$.

El hecho que en el tubo digestivo de los lactantes los enzimas de la leche materna probablemente mantengan algo de su actividad proteolítica por algún tiempo probablemente representa una ventaja para los prematuros, en quienes durante las primeras semanas de vida la capacidad digestiva en su tubo digestivo no ha alcanzado niveles adecuados ${ }^{6}$. Por ejemplo, la mucosa gástrica de estos recién nacidos secreta niveles bajos de ácido clorhídrico, lo que posibilita que el pH gástrico postprandial llegue a valores cercanos al neutro; el pH más alto disminuye la activación de la pepsina y la actividad antimicrobiana del jugo gástrico ${ }^{28}$. La mayor velocidad de vaciamiento de las proteínas parcialmente hidrolizadas es una ventaja porque permite el descenso del pH y el retorno de la actividad bactericida en el lumen gástrico ${ }^{9,11}$. La enteroquinasa es sintetizada por los enterocitos del duodeno y activa al tripsinógeno, el quimotripsinógeno y la proelastasa y a otras proteasas pancreáticas a sus formas activas ${ }^{28}$. Si bien la enteroquinasa intestinal está activa en el intestino de los lactantes, durante las primeras semanas de vida dicha actividad equivale a $20 \%$ de los niveles de los adultos ${ }^{28}$. Durante este período la menor capacidad del páncreas de los lactantes para digerir proteínas sería compensada parcialmente por los enzimas parcialmente hidrolizadas que aporta la leche materna.

\section{Efectos extradigestivos de los péptidos de la leche materna}

Algunos de los péptidos detectados en la leche materna ejercen efectos sobre la presión arterial del lactante (e incluso de los adultos), lo que indica que son 
transportados a través del epitelio intestinal y la pared de capilares y llegan a la circulación sanguínea sin ser degradados; desde aquí deben actuar sobre los centros de control de la presión arterial en el sistema nervioso central. Se estima que la acción de estos péptidos en la etapa de lactante puede tener repercusiones en la edad adulta. Los tripéptidos Val-Pro-Pro e Ile-Pro-Pro son inhibidores del enzima convertidora de la angiotensina (ECA) mediante los mismos mecanismos que los fármacos existentes en el mercado y la magnitud de su actividad es comparable a la de dichos fármacos ${ }^{29,30}$.

Algunos péptidos derivados de la $\kappa$-caseína tienen actividad antitrombótica, probablemente porque inhiben la agregación plaquetaria; incluso se ha postulado que podrían ser útiles como fármacos en este senti$\mathrm{do}^{31,32}$.

La $\beta$-caseína es el sustrato del que se deriva un grupo de péptidos opioides muy potentes denominados $\beta$-casomorfinas, con efectos comparables en su intensidad a los de los opioides de origen vegetal o sintético. Por otra parte, la $\kappa$-caseína es el origen de una familia de péptidos denominados casoxinas que actúan como antagonistas a nivel de los receptores ${ }^{33}$. Casomorfinas y casoxinas resisten la acción de los enzimas digestivos ${ }^{34}$.

De la leche materna hidrolizada por tripsina se han aislado péptidos que estimulan la fagocitosis de los macrófagos de seres humanos y de animales y que estimulan la proliferación y maduración de linfocitos $\mathrm{T}$ natural killer de recién nacidos ${ }^{35}$.

Otros péptidos regulan el vaciamiento gástrico y modulan el peristaltismo intestinal actuando a nivel local o sistémico desde la circulación ${ }^{31,36,36 b}$.

\section{Hidrólisis de las proteínas de la leche materna y madurez fetal}

Al evaluar el grado de hidrólisis de las proteínas de la leche materna se detecta que en leche de madres de prematuros los péptidos de pequeño tamaño derivados de la caseína están presentes en proporciones más elevadas que en la leche de madres de nacidos de término. En contraste con esto, las concentraciones de las caseínas $\alpha_{\mathrm{sl}}$ y $\beta$ son más bajas en la leche de las madres cuyos hijos nacieron antes de término. Esto sugiere en la leche de las madres de prematuros se produce un mayor grado de hidrólisis de sus proteínas que cuando el niño nace a término ${ }^{37,38}$. Esto es evidente para la actividad de la plasmina, que sería mayor en la leche en el pretérmino que en la leche de embarazos de término ${ }^{7}$.

Se ha sostenido que en el tejido glandular de las madres de prematuros, las uniones impermeables entre las células de sus acinos mamarios son menos eficientes en cerrar los espacios intercelulares que en las glándulas de las madres cuyos hijos han nacido a término ${ }^{39}$.
Se postula que sería por esta causa en la leche que reciben los prematuros se alcanzarían mayores concentraciones de enzimas y activadores provenientes de la circulación sanguínea ${ }^{39}$. Como resultado, en la leche materna que reciben los prematuros se alcanzaría una mayor actividad proteolítica y mayores concentraciones de péptidos ${ }^{37}$. Otra posibilidad sería que en la leche de pretérmino los péptidos inhibidores de la actividad de enzimas tendrían menor capacidad de disminuir o inhibir la expresión de dichos enzimas.

La digestión y absorción eficiente de las proteínas, y en especial de los péptidos de origen lácteo en el intestino delgado de los prematuros, disminuiría la llegada al colon de proteína no absorbida y resultaría en procesos de putrefacción de menor intensidad, que generarían menos compuestos carcinógenos, con potencial patógeno inmediato o tardío ${ }^{40}$.

La leche de las madres que han dado a luz a término es adecuada para sus recién nacidos, pero la de las madres de prematuros frecuentemente no es capaz de satisfacer enteramente sus elevados requerimientos de nutrientes. Por eso es importante verificar que estas madres produzcan volúmenes y calidades adecuadas de leche que, además de satisfacer sus requerimientos de nutrientes, tengan capacidades funcionales que compensen, aunque sea parcialmente, las menores actividades enzimáticas del páncreas y de transporte de los enterocitos en comparación con los nacidos de tér$\operatorname{mino}^{41}$.

\section{Transporte de proteínas desde la sangre a la leche materna.}

Algunas de las proteínas presentes en la leche materna tienen su origen fuera de la glándula mamaria: en el sistema linfático, el hígado o la mucosa intestinal. Estas moléculas tienen que tener necesariamente la capacidad de ser transportadas intactas a través del endotelio de los capilares y las células acinares, manteniendo sus actividades y especificidades para hidrolizar enlaces peptídicos o ejercer efectos antimicriobianos. Este sistema de síntesis en un órgano lejano y posterior secreción en la leche probablemente representa un ahorro de energía y una mayor eficiencia para la glándula mamaria que si tuvieran que ser sintetizadas en ella. Sin embargo, como los genes que codifican algunos enzimas son los mismos en todas las células somáticas del organismo, compartir la misma secuencia de aminoácidos no significa necesariamente que algunas de las proteasas de la leche materna hayan llegado necesariamente a la glándula mamaria a través de la corriente sanguínea ${ }^{42}$. Con este criterio la ausencia de expresión de algunos genes y su ARNm en las células descamadas de los acinos, en los inmunocitos y en cé- 
lulas madres aislados de la leche materna es otro indicio de que existen sistemas de transporte de proteínas desde tejidos lejanos ${ }^{26}$. Estos mecanismos de transporte a la secreción láctea son en su gran mayoría desconocidos; por lo mismo se desconoce también cuales y cómo funcionan en la glándula mamaria.

\section{Especificidad de la hidrólisis de las proteínas de la leche en la glándula mamaria}

Los procesos de hidrólisis de las proteínas de la leche materna en la glándula mamaria afectan en mayor grado a algunas proteínas mientras que otras, que incluso pueden ser más abundantes, no sufren procesos de este tipo. Esto quiere decir que se trata de procesos selectivos y deben representar una ventaja adaptativa para la glándula mamaria y los lactantes. Por ejemplo, la lactoferrina y las inmunoglobulinas, proteínas con funciones antibacterianas, no sufren hidrólisis enzimática en la glándula y mantendrían su actividad bactericida tanto en la leche como en el tubo digestivo ${ }^{43}$. Algunos de los péptidos liberados por hidrólisis enzimática en la glándula mamaria humana tienen homólogos en especies animales, por ejemplo en vacunos, lo que indica un origen lejano en la evolución de las especies de mamíferos.

\section{Modificaciones del funcionamiento de la glán- dula mamaria y la composición de la leche en procesos patológicos.}

Al generar péptidos antimicrobianos e inhibidores de algunos enzimas proteolíticos durante la lactancia, los procesos de hidrólisis de proteínas en la glándula mamaria contribuirían a protegerla de procesos de inflamatorios (mastitis) así como a su control y mejoría ${ }^{44}$. Por otra parte, es posible que los enzimas que intervienen en la hidrólisis de proteínas de la leche y de algunas otras que forman parte de la estructura de los tejidos de la glándula misma, participarían en los procesos de involución de la glándulasdespués del destete.

La mastitis se asocia con aumentos de los recuentos de células cuyo origen es la leche materna, el torrente sanguíneo o el sistema linfático. En el ganado vacuno, estas células y/o sus enzimas son marcadores de la presencia de mastitis y la leche producida por estos animales debe ser descartada por representar un peligro para la salud humana. Los principales marcadores de inflamación son la plasmina y su zimógeno, el plasminógeno, la elastasa y las catepsinas D y B, que provienen de leucocitos neutrófilos llegados desde la circulación ${ }^{45}$. También hay que considerar que las bacterias que causan la mastitis liberan en la leche sus propios enzimas que, además de causar proteólisis, dañan el tejido mamario y pueden enfermar al consumidor ${ }^{46-48}$.

Teniendo en cuenta la calidad de las proteínas de la leche humana así como las identidades y actividades de sus enzimas y péptidos, el desarrollo y aplicación de metódicas de transcriptómica, proteómica y técnicas de bioinformática permitirán evaluar de mejor manera su funcionamiento y significado fisiológico. Además, se abre la posibilidad de su síntesis en procesos industriales que los pondrán al alcance de quienes lo requie$\operatorname{ran}^{49}$.

Los procesos de hidrólisis de las proteínas en la leche materna tienen cualidades únicas e inimitables y representan ventajas específicas para la nutrición del lactante y su desarrollo integral. Los estudios que buscan dilucidar su significado funcional y su trascendencia ayudarán a caracterizar cómo están integrados estos sistemas y sus resultados más importantes a largo plazo para el desarrollo de los lactantes.

\section{Responsabilidades éticas}

Protección de personas y animales: Los autores declaran que los procedimientos seguidos se conformaron a las normas éticas del comité de experimentación humana responsable y de acuerdo con la Asociación Médica Mundial y la Declaración de Helsinki.

Confidencialidad de los datos: Los autores declaran que han seguido los protocolos de su centro de trabajo sobre la publicación de datos de pacientes.

Derecho a la privacidad y consentimiento informado: Los autores han obtenido el consentimiento informado de los pacientes y/o sujetos referidos en el artículo. Este documento obra en poder del autor de correspondencia.

\section{Conflicto de intereses}

El autor es Representante en Chile del Nestlé Nutrition Institute y Medical Director de Nestlé de Chile. 


\section{Referencias}

1. Oftedal OT. The origin of lactation as a water source for parchment-shelled eggs. J Mammary Gland Biol Neoplasia 2002;7:253-66.

2. Oftedal OT. The mammary gland and its origin during synapsid evolution. J Mammary Gland Biol Neoplasia 2002;7:225-52.

3. Oftedal OT. The evolution of milk secretion and its ancient origins. Animal 2012;6:355-68

4. Beck KL, Weber D, Phinney BS, et al. Comparative proteomics of human and macaque milk reveals species-specific nutrition during postnatal development. J Proteome Res 2015;14:2143-57.

5. Zhang Q, Cundiff JK, Maria SD, et al. Quatitative analysis of the human whey proteome reveals developing milk and mammary gland functions across the first year of lactation. Proteomes 2013;1:12858.

6. Olsen JV, Ong SE, Mann M Trypsin cleaves exclusively $\mathrm{C}$-terminal to arginine and lysine residues. Mol Cell Proteomics 2004;3:608-14.

7. Crudden A, Fox PF, Kelly, Alan L. Factors affecting the hydrolytic action of plasmin in milk. Int Dairy J 2005;15:305-13.

8. Khaldi N, Vijayakumar V, Dallas DC, et al. Predicting the important enzymes in human breast milk digestion. J Agric Food Chem 2014;62:7225-32.

9. Boutrou R, Gaudichon C, Dupont D, et al. Sequential release of milk proteinderived bioactive peptides in the jejunum in healthy humans. Am J Clin Nutr 2013;97:1314-23.

10. Demers-Mathieu V, Nielsen SD, Underwood MA, Borghese R, Dallas DC. Analysis of milk from mothers who delivered prematurely reveals few changes in proteases and protease inhibitors across gestational age at birth and infant postnatal age. J Nutr 2017;147:1152-59.

11. Lönnerdal B. Infant formula and infant nutrition: bioactive proteins of human milk and implications for composition of infant formulas. Am J Clin Nutr. 2014;99: 712S-17S.

12. Dallas DC, Underwood MA, Zivkovic AM, German JB. Digestion of protein in premature and term infants. J Nutr Disord Ther 2012;2:1-9.

13. Mills S, Ross RP, Hill C, Fitzgerald GF, Stanton C. Milk intelligence: mining milk for bioactive substances associated to human health. Int Dairy J 2011;21:377401.

14. Hayes M, Stanton C, Fitzgerald GF, Ross RP. Putting microbes to work: dairy fermentation, cell factories and bioactive peptides. Part II: bioactive peptide functions. Biotechnol J 2007;2:435-49.

15. Meisel H. Biochemical properties of regulatory peptides derived from milk proteins. Biopolymers 1997;43:119-28

16. Dallas DC, Guerrero A, Khaldi N, et al. Extensive in vivo human milk peptidomics reveals specific proteolysis yielding protective antimicrobial peptides. J Proteome Res 2013;12:2295-304.

17. Liepke C, Zucht HD, Forssmann WG, Ständker L. Purification of novel peptide antibiotics from human milk. J Chromatogr B Biomed Sci Appl 2001;752:369-77.

18. McGilligan KM, Thomas DW, Eckhert CD. Alpha-1-antitrypsin concentration in human milk. Pediatr Res 1987;22:26870.

19. Freed LM, York CM, Hamosh P, Mehta NR, Hamosh M. Bile salt-stimulated lipase of human milk: characteristics of the enzyme in the milk of mothers of premature and full-term infants. J Pediatr Gastroenterol Nutr 1987;6:598-604.

20. Hunt KM, Williams JE, Shafii B, et al. Mastitis is associated with increased free fatty acids, somatic cell count, and interleukin- 8 concentrations in human milk. Breastfeed Med 2013;8:105-10.

21. Spitsberg VL. Invited review: Bovine milk fat globule membrane as a potential nutraceutical. J Dairy Sci 2005;88:228994.

22. Lönnerdal B. Bioactive proteins in breast milk. J Paediatr Child Health 2013;49 Suppl 1:1-7.

23. Burgoyne RD, Duncan JS. Secretion of milk proteins. J Mammary Gland Biol Neoplasia 1998;3:275-86.

24. Berg P, Boyer H, Cohen SN. DNA-based information technologies. En: Nelson DL, Cox MM. Lehninger's' Principles of Biochemistry. New York: WH Freeman and Company. $5^{\text {a }}$ ed. 304-39.

25. Hassiotou F, Geddes DT, Hartmann PE. Cells in human milk: state of the science. J Hum Lact 2013;29:171-82.

26. Wickramasinghe $S$, Rincon G, Islas-Trejo A, Medrano JF. Transcriptional profiling of bovine milk using RNA sequencing. BMC Genomics 2012;13: 45.

27. Field CJ. The immunological components of human milk and their effect on immune development in infants. J Nutr 2005;135:1-4.

28. Lebenthal E. Textbook of gastroenterology and nutrition in infancy. New York: Raven Press. 1977.

29. Korhonen H, Pihlanto A. Technological options for the production of healthpromoting proteins and peptides derived from milk and colostrum. Curr Pharm Des 2007;13:829-43.

30. Rutella GS, Solieri L, Martini S, Tagliazucchi D. Release of the antihypertensive tripeptides valine- proline-proline and isoleucine-prolineproline from bovine milk caseins during in vitro gastrointestinal digestion. J Agric Food Chem 2016;64:8509-15.

31. Chabance B, Jollès $P$, Izquierdo $C$, et al. Characterization of an antithrombotic peptide from kappa-casein in newborn plasma after milk ingestion. Br J Nutr 1995;73:583-90.

32. Jollès $P$, Lévy-Toledano $S$, Fiat $A M$, et al. Analogy between fibrinogen and casein. Effect of an undecapeptide isolated from kappa-casein on platelet function. Eur J Biochem 1986;158:379-82.

33. Greenberg R, Groves ML, Dower HJ. Human beta-casein. Amino acid sequence and identification of phosphorylation sites. J Biol Chem 1984;259:5132-38.

34. Read LC, Lord AP, Brantl V, Koch G. Absorption of beta-casomorphins from autoperfused lamb and piglet small intestine. Am J Physiol 1990;259 (3 Pt 1):G443-52.

35. Clare DA, Catignani GL, Swaisgood HE. Biodefense properties of milk: the role of antimicrobial proteins and peptides. Curr Pharm Des 2003;9:1239-55.

36. Nongonierma AB, FitzGerald RJ. Bioactive properties of milk proteins in humans: a review. Peptides 2015;73:20-34.

36b. Wada Y, Lönnerdal B. Bioactive peptides derived from human milk proteinMechanisms of action. Nutr Biochem 2014; 25: 503-14.

37. Dallas DC, Smink CJ, Robinson RC, et al. Endogenous human milk peptide release is greater after preterm birth than term birth. J Nutr 2015;145:425-33.

38. Molinari CE, Casadio YS, Hartmann BT, Livk A, Bringans S, Arthur PG, Hartmann PE. Proteome mapping of human skim milk proteins in term and preterm milk. J Proteome Res 2012;11:1696-714.

39. Nguyen DA, Neville MC. Tight junction regulation in the mammary gland. J Mammary Gland Biol Neoplasia 1998;3:233-46.

40. Davila AM, Blachier F, Gotteland $\mathrm{M}$, et al. Intestinal luminal nitrogen metabolism: role of the gut microbiota and consequences for the host. Pharmacol Res 2013;68:95-107.

41. Mena P, Milad M, Vernal P, Escalante J. Nutrición intrahospitalaria del premature. Recomendaciones de la Rama de Neonatología de la Sociedad Chilena de Pediatría. Rev Chil Pediatr 2016;88:30521.

42. Dallas DC, Murray NM, Gan J. Proteolytic systems in milk: perspectives on the evolutionary function within the mammary gland and the infant. J Mammary Gland Biol Neoplasia 2015;20: 133-47.

43. Séverin S, Wenshui X. Milk biologically active components as nutraceuticals: 
review. Crit Rev Food Sci Nutr 2005 ;45: 645-56.

44. Guerrero A, Dallas DC, Contreras S, et al. Mechanistic peptidomics: factors that dictate specificity in the formation of endogenous peptides in human milk. Mol Cell Proteomics 2014;13:3343-51.

45. Heegaard CW, Larsen LB, Rasmussen LK, Højberg KE, Petersen TE, Andreasen PA. Plasminogen activation system in human milk. J Pediatr Gastroenterol Nutr
1997;25:159-66.

46. Le Roux Y, Laurent F, Moussaoui F. Polymorphonuclear proteolytic activity and milk composition change. Vet Res 2003;34:629-45.

47. Delgado S, García P, Fernández L, et al. Characterization of Staphylococcus aureus strains involved in human and bovine mastitis. FEMS Immunol Med Microbiol 2011;62:225-35.

48. Mediano P, Fernández L, Jiménez E, et al. Microbial Diversity in milk of women with mastitis: potential role of coagulasenegative staphylococci, viridans group streptococci, and corynebacteria. J Hum Lact 2017;33:309-18.

49. Elison E, Vigsnaes LK, Rindom Krogsgaard L, et al. Oral supplementation of healthy adults with 2'-O-fucosyllactose and lacto-N-neotetraose is well tolerated and shifts the intestinal microbiota. $\mathrm{Br} \mathrm{J}$ Nutr 2016;116:1356-68. 